\title{
Neuregulin-1 induces cancer stem cell characteristics in breast cancer cell lines
}

\author{
HOISEON JEONG ${ }^{1}$, JINKYOUNG KIM ${ }^{2}$, YOUNGSEOK LEE ${ }^{2}$, JAE HONG SEO ${ }^{3}$, \\ SUNG RAN HONG ${ }^{1}$ and AEREE KIM ${ }^{2}$
}

\begin{abstract}
${ }^{1}$ Department of Pathology, Cheil General Hospital and Women's Healthcare Center, Kwandong University College of Medicine, Jung-gu, Seoul 100-380; ${ }^{2}$ Department of Pathology and ${ }^{3}$ Division of Hematology-Oncology, Department of Medicine, Korea University Guro Hospital, Korea University College of Medicine,
\end{abstract}

Guro-gu, Seoul 152-703, Republic of Korea

Received March 24, 2014; Accepted June 19, 2014

DOI: $10.3892 /$ or.2014.3330

\begin{abstract}
In breast cancer, neuregulin-1 (NRG1) is known as a ligand for the HER3 receptor, which has no intrinsic tyrosine kinase activity. When activated by NRG1 binding, the HER3 receptor forms a heterodimer with other HER family receptors and mediates downstream signaling pathways, leading to multiple effects including growth, proliferation, decreased apoptosis, cellular migration and angiogenesis. Cancer stem cells (CSCs), a subgroup of cancer cells, are considered to have features of stem cells such as self-renewal ability and pluripotent differentiation into other types of mature cells. This study showed that NRG1 treatment induced CSC characteristics in breast cancer cell lines. Using breast cancer cell lines, MCF-7, SKBr-3 and MDA-MB 468, changes related to CSC characteristics were analyzed. Flow cytometry was used to analyze changes in CSC fractions in multiple cell lines after NRG1 treatment. Western blot analysis and immunofluorescence staining demonstrated the expression of CSC markers. To confirm that NRG1 treatment acts through the HER3 receptor, inhibition studies using small interfering RNA (siRNA) were performed. In MCF-7 and SKBr-3 cells, increases in the CSC fraction and expression of CSC markers were observed after NRG1 treatment. However, MDA-MB 468 cells showed high intrinsic expression of CSC markers and a high cellular fraction of CSCs, and in these cells, NRG1 treatment caused no significant change in CSC characteristics. Inhibition of the HER3 receptor blocked the NRG1-induced CSC characteristics, indicating that NRG1 functions through the HER3 receptor. The results imply the presence of a mechanism by which the HER receptors, activated by NRG1, contribute to the acquisition of CSC-like characteristics in some types of breast cancer.
\end{abstract}

Correspondence to: Professor Aeree Kim, Department of Pathology, Korea University Guro Hospital, Korea University College of Medicine, 148 Gurodong-ro, Guro-gu, Seoul 152-703, Republic of Korea E-mail: ark@korea.ac.kr

Key words: neuregulin, HER3, breast cancer, cancer stem cell

\section{Introduction}

Neuregulin-1 (NRG1) was originally identified by its ability to stimulate the phosphorylation of HER2 receptor tyrosine kinase (1). A large number of different isoforms are produced through the alternative splicing of the $N R G 1$ gene, including heregulins (HRGs), glial growth factors (GGFs) and sensory and motor neuron-derived factor (SMDF). Furthermore, the isoforms are tissue-specifically expressed, and through interaction with HER receptors, NRG1 isoforms induce the growth and differentiation of epithelial, neuronal, glial and other types of cells (2).

NRG1 is known as a ligand for the HER3 receptor, which has no intrinsic tyrosine kinase activity. HER3 receptors activated by NRG1 binding form heterodimers with other HER family receptors and mediate downstream signaling pathways. HER2-HER3 have been shown to be a potent signaling pair in preclinical models of HER2-positive breast cancer. Signals from dimerized, activated HER receptors can impact downstream signaling cascades, such as the mitogen-activated protein kinase (MAPK) pathway, the Janus tyrosine kinase (JAK)/signal transducer and activator of transcription (STAT) pathway and the phosphatidylinositol 3'-kinase (PI3K)-Akt pathway, leading to multiple effects, including growth, proliferation, decreased apoptosis, cellular migration and angiogenesis (3-8)

Research using breast cancer cell lines has shown that NRG1, the ligand of HER3, induces epithelial-mesenchymal transition (EMT) in breast cancer cells, induces expression of proteins that are involved in invasion and metastasis (e.g., matrix metalloproteinase) and drives tyrosine kinase inhibitor-resistant growth and invasion of breast cancer cells (9-11).

In EMT, epithelial cells lose cell-cell contact, transform to take on a spindle shape and express mesenchymal cell proteins, which are favorable for cellular migration and invasion (12-14). Studies suggesting that EMT accompanies cancer stem cell-like characteristics have recently come into the spotlight. Cancer stem cells (CSCs), a subgroup of cancer cells, display features of stem cells such as the abilities of self-renewal and pluripotent differentiation into other types of mature cells (15). CSCs and their relationships with 
tumor recurrence, metastasis and chemoresistance have lately drawn much attention (16-19). In human cancer, a relationship between the malignant potential of cancer and the proportion of CSCs present has been reported $(15,20,21)$. Meanwhile, various growth factors such as transforming growth factor $\beta$ (TGF- $\beta$ ) and epidermal growth factor (EGF) have been found to induce the signaling pathways related to EMT and CSC-like characteristics (22-26). These results may indicate that expression of CSC characteristics is a transient, common and dynamic process according to the tumor microenvironment during cancer progression (27).

The aim of this study was to determine whether NRG1 induces CSC characteristics in breast cancer cells and whether the induced CSC characteristics are a transient and dynamic process. Using breast cancer cell lines, MCF-7, SKBr-3 and MDA-MB 468, changes related to CSC characteristics were observed following NRG1 treatment.

\section{Materials and methods}

Cell culture. Breast cancer cell lines SKBr-3, MCF-7, T47D, Hs578T, MDA-MB 231, MDA-MB 453 and MDA-MB 468 were obtained from the American Type Culture Collection (ATCC; Rockville, MD, USA). Cells were grown in RPMI-1640 medium (Gibco, Grand Island, NY, USA) containing 100 units/ml penicillin, $100 \mathrm{mg} / \mathrm{ml}$ streptomycin (Gibco-BRL, USA) and $10 \%$ fetal bovine serum (FBS; Gibco-BRL) at $37^{\circ} \mathrm{C}$ under a humidified 95-5\% (v/v) mixture of air and $\mathrm{CO}_{2}$. Cells were harvested by trypsinization, and $2 \times 10^{6}$ cells were seeded in a $100-\mathrm{mm}$ culture dish.

For experiments, cells were incubated in serum-free medium for $16 \mathrm{~h}$. After $16 \mathrm{~h}$ of serum starvation, cells in the test group were treated with human heregulin (HRG)- $\beta 1$ $(25 \mathrm{ng} / \mathrm{ml})$ in serum-free medium for a specified period of time. HRG- $\beta 1$ is a well-known isoform of NRG1. Cells in the control group were incubated in serum-free medium for the same time but without any treatment. Recombinant human HRG- $\beta 1$ (purity >97\%) was purchased from R\&D Systems (Minneapolis, MN, USA) and aliquoted in small amounts in PBS and stored at $-70^{\circ} \mathrm{C}$.

Flow cytometry. Cells were mechanically harvested from $100-\mathrm{mm}$ culture dishes and resuspended in fluorescence-activated cell sorting buffer [ $2 \%$ bovine serum albumin (BSA) in PBS]. Cells were incubated with anti-CD44-FITC $\left(20 \mu 1 / 10^{6}\right.$ cells), anti-CD24-PE (20 $\mu 1 / 10^{6}$ cells), or isotype-matched IgG for $20 \mathrm{~min}$ at room temperature. Anti-CD44-FITC, anti-CD24 $\mathrm{PE}$ and isotype-matched $\mathrm{IgG}$ were obtained from Immunotech, a Beckman Coulter Co. (Marseille, France). After fixation, all samples were analyzed using a Cytomics FC500 (Beckman Coulter) within $2 \mathrm{~h}$.

Western blot analysis. Cells were harvested mechanically and lysed with RIPA buffer containing $20 \mathrm{mM}$ Tris- $\mathrm{HCl}$ (pH 7.5), $2 \mathrm{mM}$ EDTA, $150 \mathrm{mM} \mathrm{NaCl}, 1 \mathrm{mM}$ sodium vanadate, $10 \mathrm{mM} \mathrm{NaF}, 2.5 \mathrm{mM}$ sodium pyrophosphate, $1 \%$ sodiumdeoxycholate, $0.1 \%$ SDS, $1 \%$ NP-40, $1 \mathrm{mM}$ PMSF and a protease inhibitor cocktail (Roche, Germany). Cell lysates were cleared by centrifugation at $14,000 \mathrm{rpm}$ for $20 \mathrm{~min}$ at $4^{\circ} \mathrm{C}$, and the supernatants were used as total cellular protein.
The protein concentration of each sample was determined using a BCA protein assay kit (Pierce, Rockford, IL, USA). Proteins were electrophoresed on a sodium dodecyl sulfate (SDS)-polyacrylamide gel and transferred onto polyvinylidene fluoride membranes (Bio-Rad, USA) in a transfer buffer. The blocked membranes were then incubated with the indicated antibodies, and immunoreactive bands were developed by an enhanced chemiluminescence detection kit (Amersham Pharmacia Biotech) using secondary antibodies coupled with horseradish peroxidase.

Antibodies for CD44 (8E2), HER1/epidermal growth factor receptor and HER2/ErbB2 were obtained from Cell Signaling Technology (Beverly, MA, USA). Antibodies for HER3/ErbB3 and HER4/ErbB4 were obtained from Santa Cruz Biotechnology, Inc. (Santa Cruz, CA, USA). The antibody for CD49f (integrin $\alpha 6$ ) was purchased from Millipore (Temecula, CA, USA). The CD29 (integrin $\beta 1$ ) antibody was from BD Biosciences (San Diego, CA, USA), while monoclonal anti- $\beta$-actin was obtained from Sigma (St. Louis, MO, USA). The anti-mouse immunoglobulin horseradish peroxidase-linked $\mathrm{F}(\mathrm{ab}) 2$ fragment was from Perkin-Elmer (Boston, MA, USA).

Immunofluorescence. Approximately $2 \times 10^{4}$ cells were seeded on a 2-well Lab-Tek ${ }^{\mathrm{TM}}$ II chamber slide ${ }^{\mathrm{TM}}$ (Thermo Fisher Scientific Inc., USA). After $16 \mathrm{~h}$ of serum starvation, the cells in the test group were treated with HRG- $\beta 1(25 \mathrm{ng} / \mathrm{ml})$ (R\&D Systems) in serum-free medium for $24 \mathrm{~h}$. Cells in the control group were incubated in serum-free medium for the same amount of time without any treatment. Then, cells were washed three times with PBS and fixed with $4 \%$ paraformaldehyde for $10 \mathrm{~min}$. Following three washes with PBS, cells were permeabilized for 20 min with $0.1 \%$ Triton X-100. After being again washed in PBS, the slides were blocked with $3 \%$ BSA for $1 \mathrm{~h}$ at room temperature, and the cells were incubated with mouse monoclonal anti-CD44 primary antibodies (Cell Signaling Technology) overnight at $4^{\circ} \mathrm{C}$. After three washes, the cells were incubated with Alexa fluor ${ }^{\circledR} 488$ anti-mouse IgG secondary antibodies (Invitrogen, New Zealand). Following further washing, cells were mounted with mounting medium containing DAPI (Vector Laboratories, Burlingame, CA, USA) and observed by a Zeiss LSM 700 confocal laser scanning microscope (Carl Zeiss, Thornwood, NY, USA).

Small interfering RNA (siRNA) transfection. For transfection, SKBr-3 and MCF-7 cells were seeded in 6-cm plates and transfection was performed under conditions described by the manufacturer (Santa Cruz Biotechnology Inc., Santa Cruz, CA, USA). After replacing media with reduced serum Opti-MEM, the cells were transfected with control siRNA or ErbB3 siRNA, using the siRNA transfection reagent system (Santa Cruz). Six hours after the incubation, the media were replaced with the standard culture media described above. After an additional 24-h incubation, the transfected cells were treated with HRG- $\beta 1(25 \mathrm{ng} / \mathrm{ml})$ and then used in the following tests.

Statistical analysis. The data are expressed as the mean value \pm SE, unless indicated otherwise. Statistical analysis was performed using a two-tailed Student's t-test. Significance was defined as $\mathrm{P}<0.05$. 


\section{Results}

Selection of breast cancer cell lines for experiments. Since NRG1 is a ligand for the HER3 receptor, the breast cancer cell lines with considerable HER3 receptor expression were selected for the experiments. It was also necessary to determine the HER family receptor expression profiles of each cancer cell line since the activated HER3 receptor forms heterodimers with other members of the HER receptor family and activates downstream signaling pathways. Using western blot analysis, the expression profiles of HER family receptors were analyzed semi-quantitatively in various cancer cell lines.

We found that MCF-7, SKBr-3, T47D, MDA-MB 453 and MDA-MB 468 cell lines all showed high levels of HER3 expression. Among these cell lines, the $\mathrm{SKBr}-3$ cell line showed the highest level of HER2 expression, while the MDA-MB 468 cell line showed the highest level of HER1 expression (Fig. 1). Based on these results, the SKBr-3 cell line with HER2-HER3 receptors and the MDA-MB 468 cell line with HER1-HER3 receptors were selected for the subsequent experiments. Using the experimental results of the SKBr-3 and MDA-MB 468 cell lines, the downstream signaling effects induced by HER2-HER3 heterodimerization and those induced by HER1-HER3 heterodimerization could be compared. In addition to SKBr-3, T47D and MDA-MB 453 cells also expressed considerable levels of HER2 and HER3. However, these cell lines were not included in the following experiments as their HER2 expression levels were lower than those of SKBr-3.

The MCF-7 cell line, which showed considerable HER3 expression in the western blot analysis, was included in the subsequent experiments since it is a well-known hormoneresponsive cell line (28). Although the relevance of a breast cancer cell line as a model for actual breast cancer is a controversial issue (29), the hormone-responsive cell line MCF-7 was considered as a model for luminal-type breast cancer in this study, while SKBr-3 with strong HER2 expression was considered as a model for HER2-type breast cancer and MDA-MB 468 with strong HER1 expression was considered as a model for basal-like type breast cancer.

NRG1 induces increases in CD44-positive CSC fractions. To test the hypothesis that NRG1 induces CSC-like properties in breast cancer cells, the expression of CSC markers was examined. How best to calculate CSCs in a complex tumor cell population is a subject of active research and controversy. In breast cancer, CSCs are usually identified by a CD $44^{\text {high }} / \mathrm{CD} 24^{\text {low }}$ phenotype (30). Using flow cytometry, the fraction of CSCs in each cell line was measured. The differences in CSC fraction between the control group cells and the NRG1 treatment group cells were analyzed.

Most SKBr-3 cells in the control group showed the CD44 $4^{\text {low }}$ CD24 $4^{\text {high }}$ phenotype (93.96\%) and no cells showed the CD44 $4^{\text {high }}$ CD $24^{\text {low }}$ phenotype. After $24 \mathrm{~h}$ of incubation with NRG1, the cellular fraction with the $\mathrm{CD} 44^{\text {low }} / \mathrm{CD} 24^{\text {high }}$ phenotype was decreased (78.65\%) and a very small fraction [50 cells $(0.8 \%)$ ] expressing the CD $44^{\text {high }} / \mathrm{CD} 24^{\text {low }}$ phenotype newly appeared. The results of flow cytometry showed an increased proportion of CD44-positive cells after NRG1 treatment, from $1.28 \%$ in

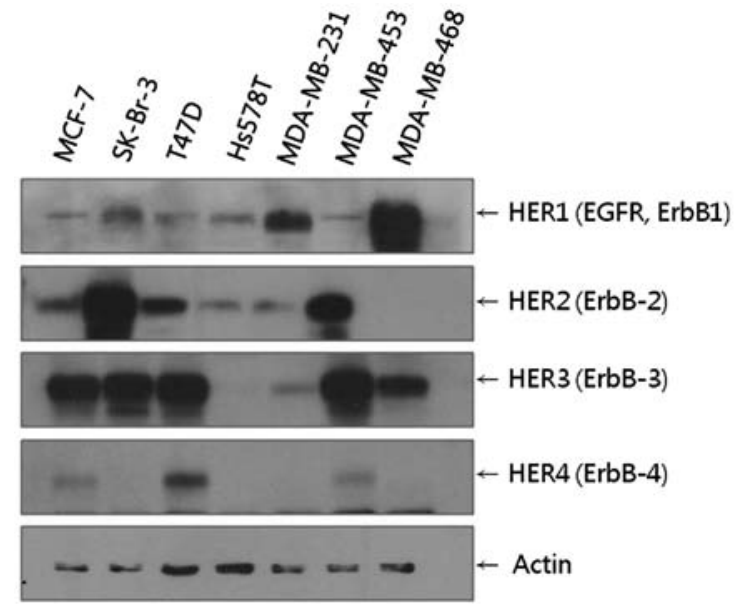

Figure 1. Expression of HER family receptors in various breast cancer cell lines. Among the breast cancer cell lines tested, the SKBr-3 cell line, which showed high expression levels of HER2/HER3 and the MDA-MB 468 cell line, which showed high expression levels of HER1/HER3, were selected for the subsequent experiments.

the control group to $9.95 \%$ in the NRG1 treatment group. The proportion of cells with CD24 expression was not significantly changed (Fig. 2).

In contrast, most of the MCF-7 and MDA-MB 468 cells in the control group exhibited the CD $44^{\text {high }} / \mathrm{CD} 24^{\text {high }}$ phenotype, with $91.91 \%$ of MCF-7 cells and $89.18 \%$ of MDA-MB 468 cells having this phenotype. Approximately $70 \%$ of $\mathrm{MCF}-7$ cells in the control group expressed CD44. NRG1 treatment induced an increase in the proportion of CD44-positive cells, up to $92 \%$. The proportion of cells with the CD $44^{\text {high }} / \mathrm{CD} 24^{\text {low }}$ phenotype also increased, from $0.06 \%$ in the control group to $0.11 \%$ in the NRG1 treatment group (Fig. 2).

Regarding MDA-MB 468 cells, NRG1 had no effect. The cellular fractions depending on the degree of CD44/CD24 expression were not significantly changed after NRG1 treatment. Unexpectedly, the proportion of cells with the CD $44^{\text {high }} / \mathrm{CD} 24^{\text {low }}$ phenotype was slightly decreased, from $0.14 \%$ in the control group to $0.10 \%$ in the NRG1 treatment group. NRG1 treatment did not make any significant changes in the proportion of CD44-positive cells (Fig. 2).

The results of the flow cytometry showed that NRG1 induced increases in the proportion of CD44-positive cells in the SKBr-3 and MCF-7 cell lines but not in the MDA-MB 468 cells. NRG1 treatment made no significant change in the proportion of CD24-positive cells in any of the three cell lines. Regarding the cells with the CD $44^{\text {high }} / \mathrm{CD} 24^{\text {low }}$ phenotype, NRG1 treatment induced new appearances of those cells in the SKBr-3 cell line and a slight increase of those cells in the MCF-7 cell line. While the SKBr-3 cell line had no cells with the CD $44^{\text {high }} / \mathrm{CD} 24^{\text {low }}$ phenotype in the control group, some of the MCF-7 and MDA-MB 468 control cells had the $\mathrm{CD} 44^{\text {high }} / \mathrm{CD} 24^{\text {low }}$ phenotype. Although the proportions of these cells were very small, it is noteworthy that these cell lines had some cells with the CSC phenotype before any treatment. Considering the high proportion of CD44-positive cells in the control group, MCF-7 and MDA-MB 468 cells are considered to contain a substantial population of CSC before treatment with NRG1. 

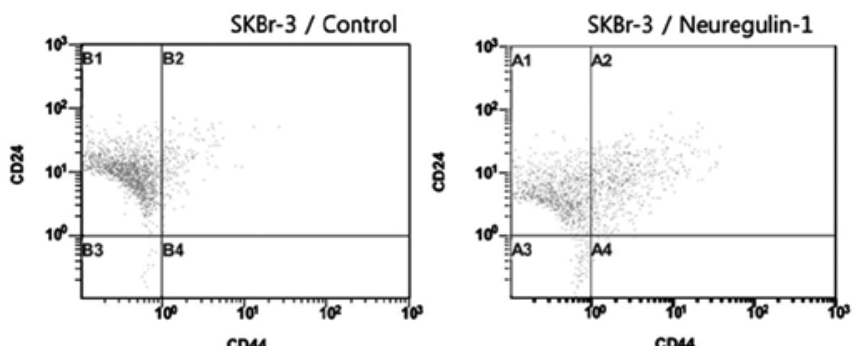

CD44

\begin{tabular}{|c|c|c|c|c|}
\hline \multirow[t]{2}{*}{ Region } & \multicolumn{2}{|c|}{ Control } & \multicolumn{2}{|c|}{ Neuregulin-1 } \\
\hline & Number & \% Total & Number & \% Total \\
\hline All & 6192 & 100.00 & 6280 & 100.00 \\
\hline 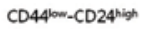 & 5818 & 93.96 & 4939 & 78.65 \\
\hline 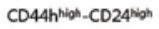 & 346 & 5.59 & 1157 & 18.42 \\
\hline$C D 4410 \%$-CD 24low & 28 & 0.45 & 134 & 2.13 \\
\hline CD $44^{\text {high. }} \cdot C D 24^{\text {low }}$ & 0 & 0.00 & 50 & 0.80 \\
\hline
\end{tabular}

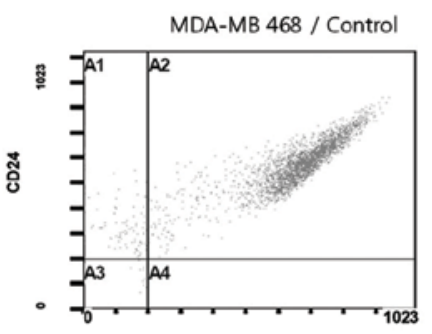

CD44

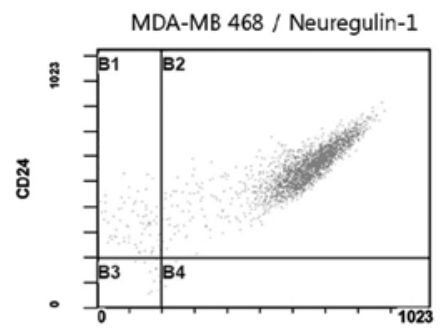

CD44

\begin{tabular}{|c|c|c|c|c|}
\hline \multirow[t]{2}{*}{ Region } & \multicolumn{2}{|c|}{ Control } & \multicolumn{2}{|c|}{ Neuregulin-1 } \\
\hline & Number & \% Total & Number & \% Total \\
\hline All & 6403 & 100.00 & 6742 & 100.00 \\
\hline CD44/6w_CD 24tion & 658 & 10.28 & 737 & 10.93 \\
\hline $\mathrm{CD} 44^{\text {high-CD }}-\mathrm{CD} 24^{\text {migh }}$ & 5710 & 89.18 & 5976 & 88.64 \\
\hline CD44/low-CD24low & 26 & 0.41 & 22 & 0.33 \\
\hline CD444high_CD24/aw & 9 & 0.14 & 7 & 0.10 \\
\hline
\end{tabular}
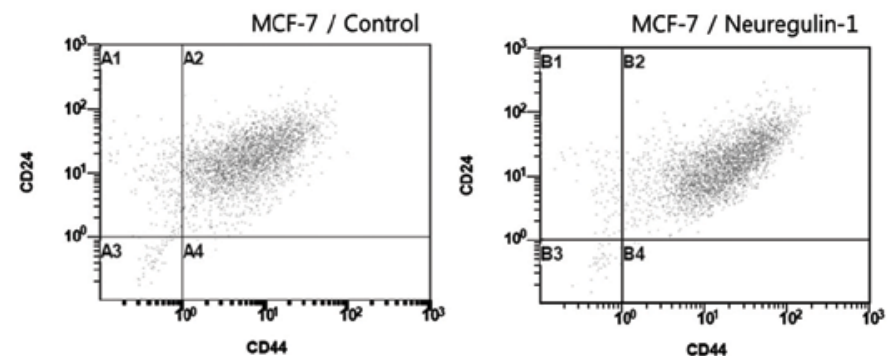

\begin{tabular}{|c|c|c|c|c|}
\hline \multirow[t]{2}{*}{ Region } & \multicolumn{2}{|c|}{ Control } & \multicolumn{2}{|c|}{ Neuregulin-1 } \\
\hline & Number & $\%$ Total & Number & \% Total \\
\hline All & 6573 & 100.00 & 7091 & 100.00 \\
\hline CD44tow-CD24high & 425 & 6.47 & 125 & 1.76 \\
\hline CD44h high-CD24hich & 6041 & 91.91 & 6910 & 97.45 \\
\hline CD44tow_CD24low & 103 & 1.57 & 48 & 0.68 \\
\hline CD44 & 4 & 0.06 & 8 & 0.11 \\
\hline
\end{tabular}
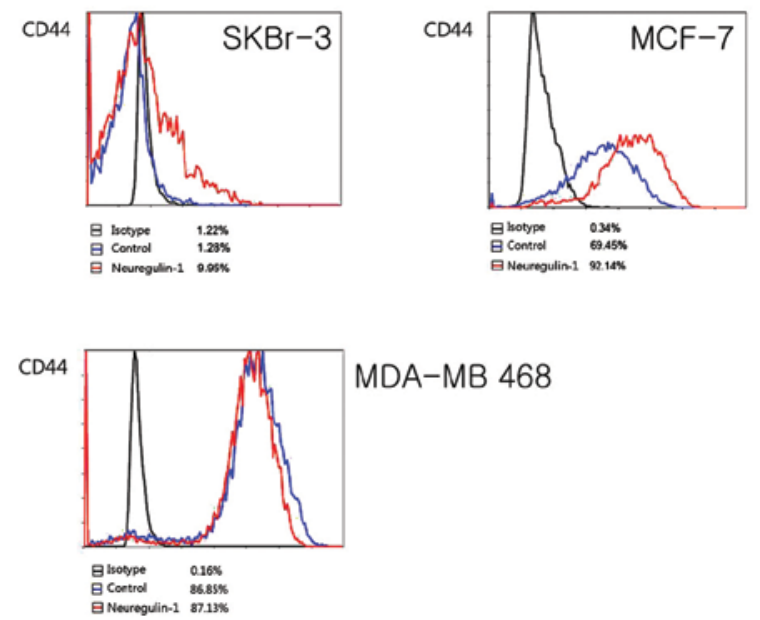

Figure 2. NRG1 induces increases in the CD44-positive CSC fraction in SKBr-3 and MCF-7 cells but not in MDA-MB 468 cells. Most SKBr-3 cells in the control group exhibited the CD $44^{\text {low }} / \mathrm{CD} 24^{\text {high }}$ phenotype. However, after $24 \mathrm{~h}$ of incubation with NRG1, the cellular fraction with the CD $44^{\text {high }} / \mathrm{CD} 24^{\text {high }}$ phenotype was increased. The results of the flow cytometry showed increased proportions of CD44-positive cells after NRG1 treatment. Most of the MCF-7 cells in the control group had the CD $44^{\text {high }} / \mathrm{CD} 24^{\text {high }}$ phenotype and $70 \%$ of MCF-7 cells in the control group expressed CD44. NRG1 treatment induced increases in the proportions of CD44-positive cells, up to 92\%. However, NRG1 treatment did not induce any significant change in the CD44-positive CSC fraction in the MDA-MB 468 cells, in which both the control group cells and the NRG1 treatment group cells predominantly showed the CD44 ${ }^{\text {high }} / \mathrm{CD} 24^{\text {high }}$ phenotype. NRG1 treatment did not induce any significant change in the proportion of CD44-positive cells or CD24-positive cells in this cell line. NRG1, neuregulin-1.

NRG1 induces the expression of CSC markers. Using western blot analysis, the expression levels of CSC markers were analyzed semi-quantitatively. In addition to CD44, integrin $\alpha 6 / C D 49 f$ and integrin $\beta 1 / C D 29$ were used as CSC markers. These integrins are generally known for their high levels of expression in normal mammary gland stem cells (MGSCs) and may also be important in breast CSCs (31-34).

In $\mathrm{SKBr}-3$ cells, the control group cells did not express CD44 or CD49f and expression of CD29 was negligible. However, after $12 \mathrm{~h}$ of incubation with NRG1, expression of CD44 and CD49f became evident in the SKBr-3 cells. The expression levels of CD44 and CD29 appeared to reach their peaks after 12-24 h of incubation. While the expression levels of CD44 and CD29 were decreased over time, the expression level of CD49f increased continuously until 96 h of NRG1 treatment (Fig. 3).

MCF-7 cells exhibited patterns of expression similar to those of SKBr-3 cells. Expression of CD29 was observed only faintly in the control cells and CD44 was almost completely absent. After $6 \mathrm{~h}$ of NRG1 treatment, expression of CD44 and CD29 became evident. Expression levels of CD44 and CD29 appeared to reach their peaks after $12-24 \mathrm{~h}$ of incubation. While the expression level of CD44 was decreased after $48 \mathrm{~h}$, the elevated expression level of CD29 was sustained until $96 \mathrm{~h}$ of treatment. Expression of CD49f was not observed in the MCF-7 cells, either in the control group or the NRG1 treatment group (Fig. 3).

NRG1-induced expression of CSC markers was verified by immunofluorescence staining. After incubating cells for 24 h with NRG1, expression of CD44 was observed in the SKBr-3 and MCF-7 cells. Furthermore, SKBr-3 cells showed an outstanding transformation into spindle-shaped cells following NRG1 treatment, suggesting that they underwent epithelial-mesenchymal transition (Fig. 4).

Due to the results of the flow cytometry, MDA-MB 468 cells were not analyzed further. 
NRG-1

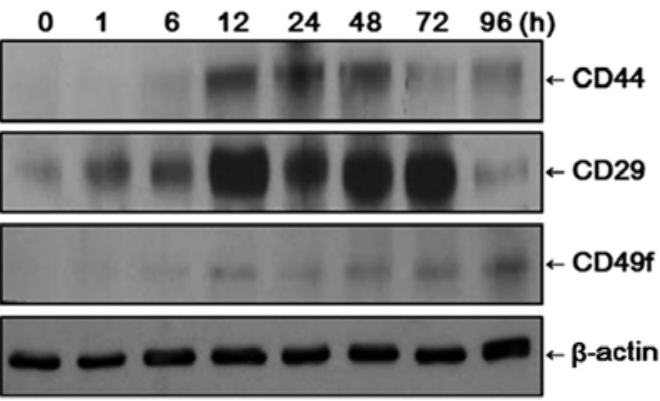

SKBr-3
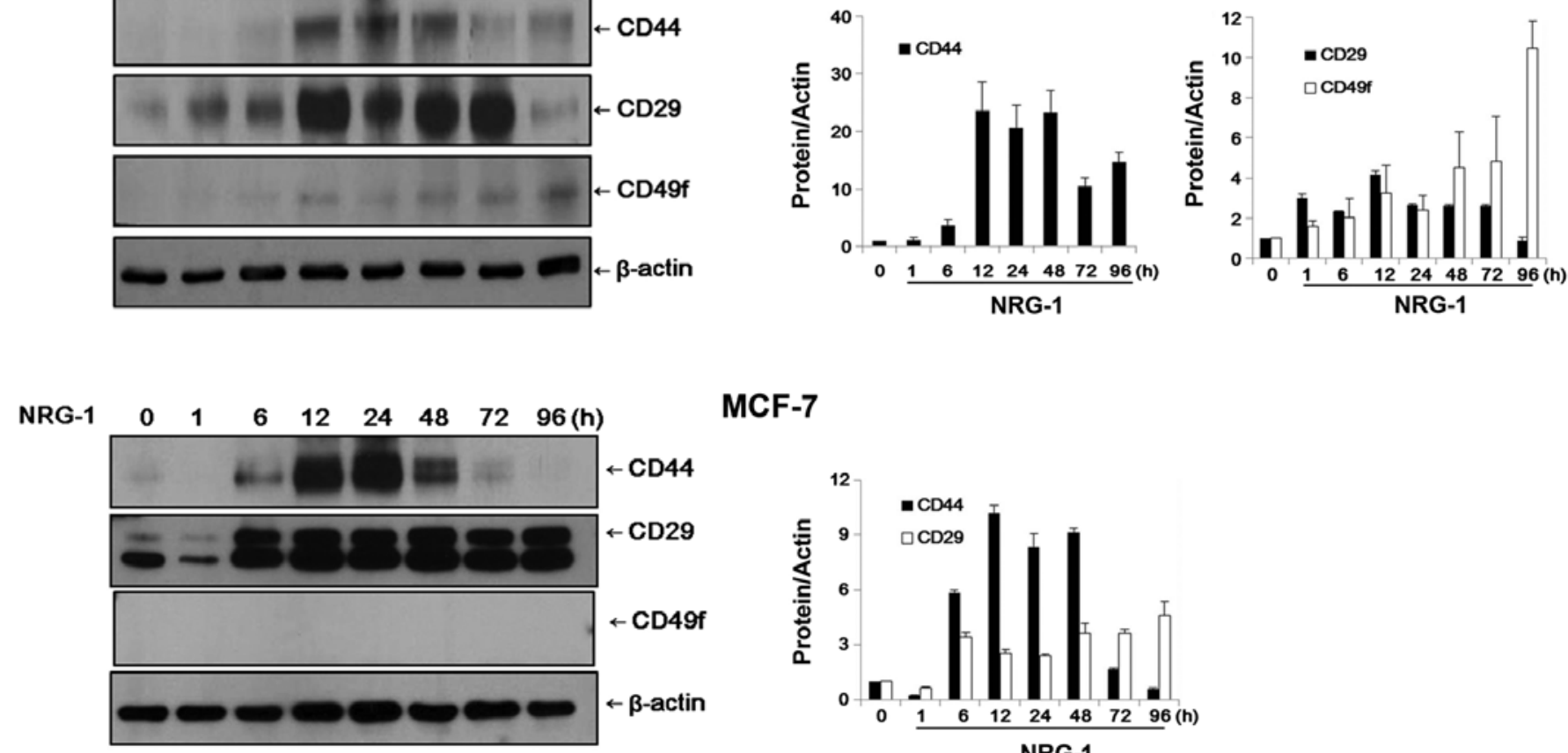

MCF-7

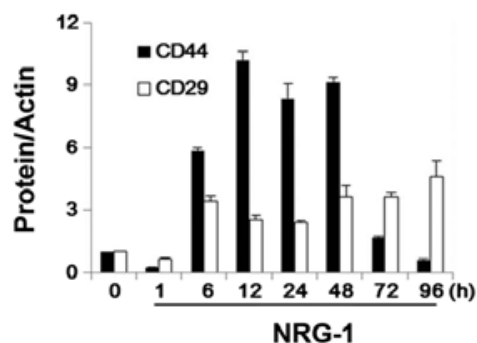

Figure 3. NRG1 induces expression of CSC markers. In the SKBr-3 cells, the control group cells did not express CD44 or CD49f, and expression of CD29 was negligible. After $12 \mathrm{~h}$ of incubation with NRG1, expression of CD44 and CD49f became evident, with the expression levels of CD44 and CD29 reaching peaks after 12-24 h of treatment. In the MCF-7 cells, expression of CD29 was observed only slightly in the control cells and CD44 was almost completely absent. After $6 \mathrm{~h}$ of incubation with NRG1, expression of CD44 and CD29 became evident, with expression levels peaking after 12-24 h. NRG1, neuregulin-1.

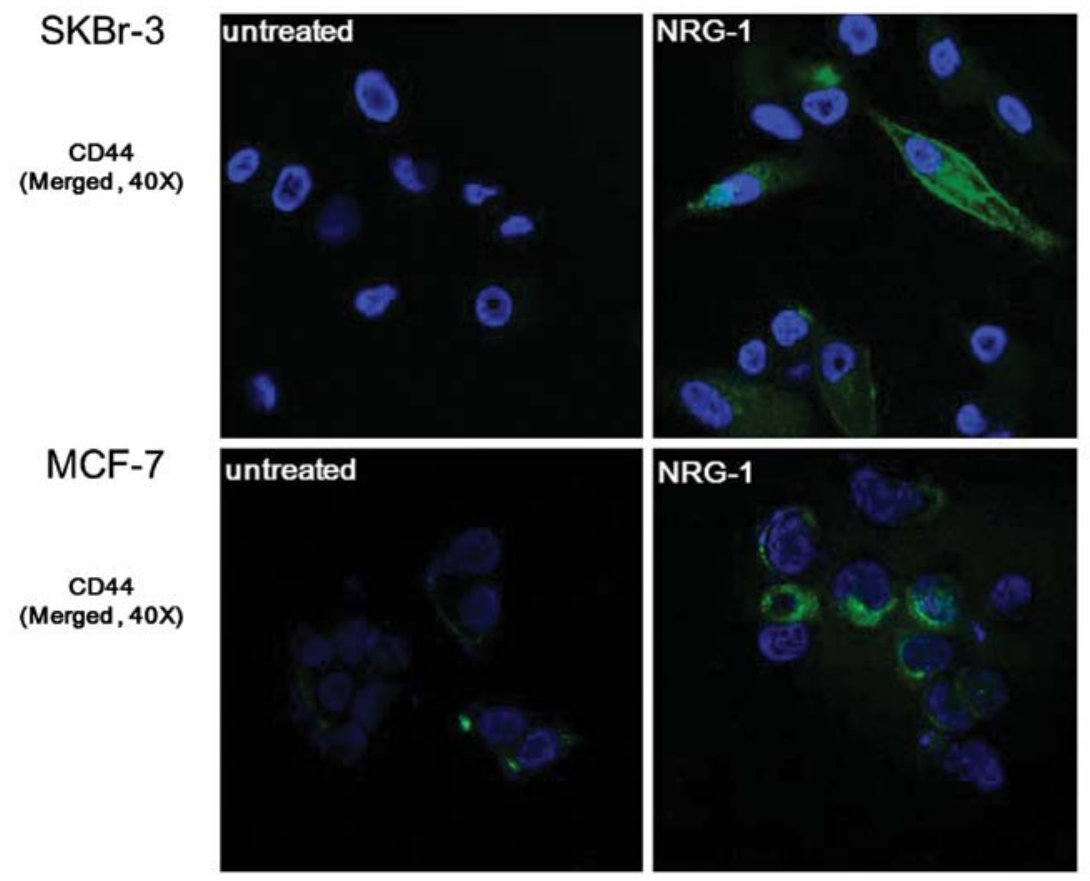

Figure 4. NRG1-induced expression of CSC markers is confirmed by immunofluorescence staining. After $24 \mathrm{~h}$ of incubation with NRG1, expression of CD44 (green) was observed in the SKBr-3 and MCF-7 cells. The representative photomicrographs show all channels imaged simultaneously. NRG1, neuregulin-1.

Inhibition of the HER 3 receptor suppresses expression of CSC markers. We found that NRG1 treatment induced increases in the CSC fraction and expression levels of CSC markers in various breast cancer cell lines. To determine whether the effects of NRG1 treatment are mediated through the HER3 receptor, we blocked the expression of the HER3 receptor using siRNA and observed any changes in CSC marker expression. After NRG1 treatment, $\mathrm{SKBr}-3$ cells treated with control siRNA showed increased expression levels of CSC markers, as expected. Meanwhile, SKBr-3 cells treated with the HER3 receptor (ErbB3) siRNA showed only minimal expression of CSC markers (Fig. 5). It was evident that the inhibition of 


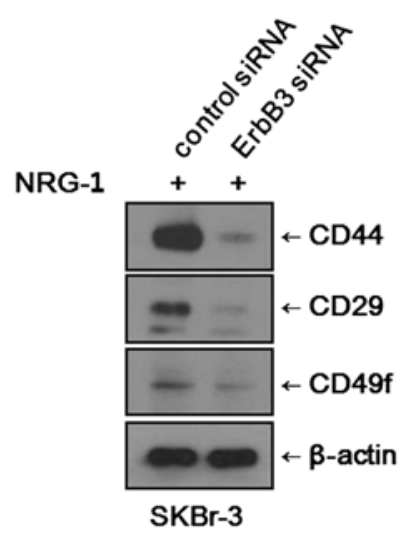

Figure 5. Inhibition of HER3 receptor suppresses expression of CSC markers. After NRG1 treatment, SKBr-3 cells transfected with control siRNA showed increased expression levels of CSC markers. In contrast, SKBr-3 cells transfected with the HER3 receptor (ErbB3) siRNA showed only faint expression of CSC markers. NRG1, neuregulin-1.

HER3 receptor counteracted the effects of NRG1 treatment. However, the experiment performed with MCF-7 cells did not show any significant changes. After NRG1 treatment, both the MCF-7 cells treated with control siRNA and those treated with HER3 receptor (ErbB3) siRNA showed similar levels of CSC marker expression.

\section{Discussion}

The present study demonstrated that NRG1 induces the expression of CSC-like characteristics in a number of breast cancer cell lines. Manifestation of CSC-like characteristics in the cells lines was examined by observing the expression of CSC markers CD44, CD29 and CD49f.

There were differences among the breast cancer cell lines in regards to the levels of expression of CSC markers. MDA-MB 468 cells had the highest CSC fraction and CSC marker expression before NRG1 treatment, and this high basal level of expression made it impossible to use the MDA-MB 468 cells to illustrate any increase in CSC properties due to NRG1 treatment. MDA-MB 468 cells display high levels of HER1 expression and are known to have low or minor expression of hormonal receptors and HER2. Because of these features, MDA-MB 468 cells are often used as a model for basal-like type of breast cancer. The result of this study suggests that the basal-like type of breast cancer cells may have a high level of CSC characteristics regardless of HER family receptor activation. Some studies using a tissue microarray of human breast cancer reported that breast cancers with basal-like phenotypes are associated with EMT $(35,36)$. Considering that EMT accompanies CSC-like characteristics, the results of the present study support those of the human breast cancer tissue microarray studies.

On the other hand, MCF-7 and SKBr-3 cells showed increased CSC fractions and expression levels of CSC markers after NRG1 treatment. This finding implies the existence of a mechanism by which the activated HER receptors contribute to the acquisition of CSC-like characteristics. It is known that signals from activated, dimerized HER receptors can impact downstream signaling cascades such as the MAPK pathway, the JAK/STAT pathway and the PI3K/Akt pathway, leading to multiple effects $(4,6,37,38)$. Acquisition of CSC-like characteristics could be the result of one of these multiple effects. Some studies have shown that NRG1 induces EMT in breast cancer cells and induces expression of proteins related to invasion and metastasis by cancer cells (e.g., matrix metalloproteinase) (9-11). Therefore, activation of HER receptors by NRG1 induces EMT and CSC-like characteristics in tumor cells and ultimately the acquisition of a phenotype that is favorable for the survival of the tumor cell. NRG1 is a tissue-specifically expressed growth factor that normally affects variable types of cells. It may have a role in the settlement of circulating tumor cells and the formation of metastatic tumor masses, particularly in some specific sites, such as the brain and liver, in which normal parenchymal cells express NRG1.

Regarding the expression of CSC markers, the results of our western blot analysis showed another significant finding. In SKBr-3 and MCF-7 cells, the expression levels of CSC markers reached a peak after 12-24 h of incubation with NRG1. After that time, the expression levels of most CSC markers, particularly CD44, showed a decreasing trend with the passage of time. This result suggests that the expression of CSC characteristics is a transient and reversible phenomenon. This finding supports the hypothesis that the expression of CSC characteristics is a transient and dynamic process that can advance or retreat according to the tumor microenvironment during cancer progression (27).

It is possible that NRG1-induced CSC-like characteristics may play a role in a mechanism of chemoresistance. Studies have shown that activation of HER receptors and their downstream signaling cascades may be related to the resistance of cancer cells to chemotherapy and hormonal therapy (39). Particularly, HER2-HER3 dimerization appears to play a role as a scavenger of HER2-targeted therapy and contributes to the restoration of the malignant phenotype of breast cancers cells $(40,41)$. Unpublished data from our laboratory revealed that the expression level of NRG1 is elevated in tamoxifen-resistant MCF-7 cells. It is assumed that chemoresistant tumor cells secrete NRG1 and activate autocrine induction of HER receptor-related downstream signals. As a consequence, the tumor cells may then be induced to express proteins related to the EMT and acquisition of CSC-like properties to ultimately attain a more favorable phenotype for survival.

Although this study is a novel one, it has some limitations. The acquisition of CSC characteristics was evaluated using expression of cancer stem cell markers only. It was not confirmed that the cells which expressed CSC markers had self-renewal activity or pluripotent differentiation potential. In addition, the highly tumorigenic nature of these cells needs to be demonstrated through mammosphere assays or xenografts in NOD/SCID mice.

In summary, the present study revealed that NRG1 treatment induces CSC characteristics in breast cancer cell lines. In MCF-7 and SKBr-3 cells, increases in the CSC fraction and expression levels of CSC markers were observed after NRG1 treatment. However, MDA-MB 468 cells showed high intrinsic expression of CSC markers and a high cellular fraction of CSCs. In the MDA-MB 468 cells, NRG1 treatment induced no significant change in CSC characteristics. 
These results imply the existence of a mechanism by which HER receptors activated by NRG1 contribute to the acquisition of CSC-like characteristics in certain types of breast cancer. CSCs are known to be related to tumor recurrence and metastasis, chemoresistance and poor prognosis. This mechanism could be a strategy through which tumor cells that have been activated by NRG1 gain a favorable phenotype for survival. Understanding the mechanism of action of NRG1 and HER receptors could be a clue to overcoming the chemoresistance observed in certain types of cancers. Furthermore, NRG1, HER receptors and the downstream signaling molecules could serve as new targets for cancer therapeutics.

\section{References}

1. Holmes WE, Sliwkowski MX, Akita RW, et al: Identification of heregulin, a specific activator of p185erbB2. Science 256 1205-1210, 1992.

2. Britsch S: The neuregulin-I/ErbB signaling system in development and disease. Adv Anat Embryol Cell Biol 190: 1-65, 2007.

3. Atlas E, Cardillo M, Mehmi I, Zahedkargaran H, Tang C and Lupu R: Heregulin is sufficient for the promotion of tumorigenicity and metastasis of breast cancer cells in vivo. Mol Cancer Res 1: 165-175, 2003.

4. Vijapurkar U,Kim MS and Koland JG: Roles of mitogen-activated protein kinase and phosphoinositide 3'-kinase in ErbB2/ErbB3 coreceptor-mediated heregulin signaling. Exp Cell Res 284: 291-302, 2003

5. Hsieh AC and Moasser MM: Targeting HER proteins in cancer therapy and the role of the non-target HER3. Br J Cancer 97: 453-457, 2007

6. Olayioye MA, Neve RM, Lane HA and Hynes NE: The ErbB signaling network: receptor heterodimerization in development and cancer. EMBO J 19: 3159-3167, 2000.

7. Lupu R, Cardillo M, Cho C, et al: The significance of heregulin in breast cancer tumor progression and drug resistance. Breast Cancer Res Treat 38: 57-66, 1996.

8. Hijazi MM, Thompson EW, Tang C, et al: Heregulin regulates the actin cytoskeleton and promotes invasive properties in breas cancer cell lines. Int J Oncol 17: 629-641, 2000.

9. Cheng L, Zha Z, Lang B, Liu J and Yao X: Heregulin-beta1 promotes metastasis of breast cancer cell line SKBr-3 through upregulation of Snail and induction of epithelial-mesenchymal transition. Cancer Lett 280: 50-60, 2009.

10. Yuan G, Qian L, Song L, et al: Heregulin-beta promotes matrix metalloproteinase-7 expression via HER2-mediated AP-1 activation in MCF-7 cells. Mol Cell Biochem 318: 73-79, 2008

11. Cho SJ, Chae MJ, Shin BK, Kim HK and Kim A: Akt- and MAPK-mediated activation and secretion of MMP-9 into stroma in breast cancer cells upon heregulin treatment. Mol Med Rep 1: $83-88,2008$

12. Guarino M, Rubino B and Ballabio G: The role of epithelialmesenchymal transition in cancer pathology. Pathology 39: 305-318, 2007.

13. Kokkinos MI, Wafai R, Wong MK, Newgreen DF, Thompson EW and Waltham M: Vimentin and epithelial-mesenchymal transition in human breast cancer - observations in vitro and in vivo. Cells Tissues Organs 185: 191-203, 2007.

14. Micalizzi DS, Farabaugh SM and Ford HL: Epithelialmesenchymal transition in cancer: parallels between normal development and tumor progression. J Mammary Gland Biol Neoplasia 15: 117-134, 2010.

15. Ebben JD, Treisman DM, Zorniak M, Kutty RG, Clark PA and Kuo JS: The cancer stem cell paradigm: a new understanding of tumor development and treatment. Expert Opin Ther Targets 14 621-632, 2010

16. Blick T, Hugo H, Widodo E, et al: Epithelial mesenchymal transition traits in human breast cancer cell lines parallel the CD44(hi/)CD24(lo/-) stem cell phenotype in human breast cancer. J Mammary Gland Biol Neoplasia 15: 235-252, 2010.

17. Creighton CJ, Chang JC and Rosen JM: Epithelial-mesenchymal transition (EMT) in tumor-initiating cells and its clinical implications in breast cancer. J Mammary Gland Biol Neoplasia 15: $253-260,2010$
18. Mani SA, Guo W, Liao MJ, et al: The epithelial-mesenchymal transition generates cells with properties of stem cells. Cell 133: 704-715, 2008

19. May CD, Sphyris N, Evans KW, Werden SJ, Guo W and Mani SA: Epithelial-mesenchymal transition and cancer stem cells: a dangerously dynamic duo in breast cancer progression. Breast Cancer Res 13: 202, 2011

20. Almqvist PM, Mah R, Lendahl U, Jacobsson B and Hendson G: Immunohistochemical detection of nestin in pediatric brain tumors. J Histochem Cytochem 50: 147-158, 2002.

21. Dahlstrand J, Collins VP and Lendahl U: Expression of the class VI intermediate filament nestin in human central nervous system tumors. Cancer Res 52: 5334-5341, 1992.

22. Miyazono K: Transforming growth factor-beta signaling in epithelial-mesenchymal transition and progression of cancer. Proc Jpn Acad Ser B Phys Biol Sci 85: 314-323, 2009.

23. Taylor MA, Parvani JG and Schiemann WP: The pathophysiology of epithelial-mesenchymal transition induced by transforming growth factor-beta in normal and malignant mammary epithelial cells. J Mammary Gland Biol Neoplasia 15: 169-190, 2010.

24. Wang $\mathrm{H}$, Wu J, Zhang Y, et al: Transforming growth factor $\beta$ induced epithelial-mesenchymal transition increases cancer stem-like cells in the PANC-1 cell line. Oncol Lett 3: 229-233, 2012.

25. Hardy KM, Booth BW, Hendrix MJ, Salomon DS and Strizzi L: ErbB/EGF signaling and EMT in mammary development and breast cancer. J Mammary Gland Biol Neoplasia 15: 191-199, 2010.

26. Kim J, Jung J, Lee SJ, Lee JS and Park MJ: Cancer stem-like cells persist in established cell lines through autocrine activation of EGFR signaling. Oncol Lett 3: 607-612, 2012.

27. Li Y and Laterra J: Cancer stem cells: distinct entities or dynamically regulated phenotypes? Cancer Res 72: 576-580, 2012.

28. Levenson AS and Jordan VC: MCF-7: the first hormone-responsive breast cancer cell line. Cancer Res 57: 3071-3078, 1997.

29. Lacroix M and Leclercq G: Relevance of breast cancer cell lines as models for breast tumours: an update. Breast Cancer Res Treat 83: 249-289, 2004

30. Al-Hajj M, Wicha MS, Benito-Hernandez A, Morrison SJ and Clarke MF: Prospective identification of tumorigenic breast cancer cells. Proc Natl Acad Sci USA 100: 3983-3988, 2003.

31. Cariati M, Naderi A, Brown JP, et al: Alpha-6 integrin is necessary for the tumourigenicity of a stem cell-like subpopulation within the MCF-7 breast cancer cell line. Int J Cancer 122: 298-304, 2008

32. Shackleton M, Vaillant F, Simpson KJ, et al: Generation of a functional mammary gland from a single stem cell. Nature 439: 84-88, 2006

33. Taddei I, Deugnier MA, Faraldo MM, et al: Beta1 integrin deletion from the basal compartment of the mammary epithelium affects stem cells. Nat Cell Biol 10: 716-722, 2008.

34. White DE, Kurpios NA, Zuo D, et al: Targeted disruption of betal-integrin in a transgenic mouse model of human breast cancer reveals an essential role in mammary tumor induction. Cancer Cell 6: 159-170, 2004.

35. Sarrio D, Rodriguez-Pinilla SM, Hardisson D, Cano A, Moreno-Bueno G and Palacios J: Epithelial-mesenchymal transition in breast cancer relates to the basal-like phenotype. Cancer Res 68: 989-997, 2008.

36. Jeong H, Ryu YJ, An J,Lee Y and Kim A: Epithelial-mesenchymal transition in breast cancer correlates with high histological grade and triple-negative phenotype. Histopathology 60: E87-E95, 2012.

37. Kim S, Choi JH, Lim HI, et al: EGF-induced MMP-9 expression is mediated by the JAK3/ERK pathway, but not by the JAK3/STAT-3 pathway in a SKBr-3 breast cancer cell line. Cell Signal 21: 892-898, 2009.

38. Park S, Jung HH, Park YH, Ahn JS and Im YH: ERK/MAPK pathways play critical roles in EGFR ligands-induced MMP1 expression. Biochem Biophys Res Commun 407: 680-686, 2011.

39. Frogne T, Benjaminsen RV, Sonne-Hansen K, et al: Activation of ErbB3, EGFR and Erk is essential for growth of human breast cancer cell lines with acquired resistance to fulvestrant. Breast Cancer Res Treat 114: 263-275, 2009.

40. Garrett JT, Olivares MG, Rinehart C, et al: Transcriptional and posttranslational up-regulation of HER3 (ErbB3) compensates for inhibition of the HER2 tyrosine kinase. Proc Natl Acad Sci USA 108: 5021-5026, 2011.

41. Sergina NV, Rausch M, Wang D, et al: Escape from HER-family tyrosine kinase inhibitor therapy by the kinase-inactive HER3. Nature 445: 437-441, 2007. 